\title{
Exploring culture through in-depth interviews: is it useful to ask people about what they think, mean, and do?
}

\author{
EXPLORANDO FENÓMENOS CULTURALES A TRAVÉS DE ENTREVISTAS EN PROFUNDIDAD: ¿DE QUÉ SIRVE \\ PREGUNTAR A LAS PERSONAS ACERCA DE LO QUE PIENSAN, DE LO QUE QUIEREN DECIR Y DE LO QUE \\ HACEN?
}

Ricardo Rivas (ricardorivas@email.arizona.edu) School of Sociology, University of Arizona (Tucson, United States of America) ORCID: 0000-0002-7160-7729

Michael Gibson-Light (mgibson@email.arizona.edu) School of Sociology, University of Arizona (Tucson, United States of America) ORCID: 0000-0003-2445-2389

\begin{abstract}
In 2010, American sociologist John Levi Martin asserted that in-depth interviews are inadequate for the study of culture. This sparked a debate in the discipline over the legitimacy of interview methods for researchers of culture and others. Here, we contextualize and contribute to this debate. We review the ideas of Martin and argue that in-depth interviews are in fact valid, well-supported in the field, and useful for investigating cultural phenomena. We build this counter-argument on three angles: epistemological, theoretical and methodological. Given this defense, we also explore how social scientists are implementing innovative ways to complement in-depth interview approaches, such as through social network analysis.
\end{abstract}

Key words: qualitative methods, in-depth interviews, epistemology, sociology of culture, John Levi Martin.

\section{Resumen}

En el año 2010, John Levi Martin, un reconocido sociólogo estadounidense dedicó una de sus publicaciones para aseverar que las entrevistas en profundidad eran inadecuadas para estudiar fenómenos culturales. Esto desató un debate en la disciplina respecto a la legitimidad de los métodos basados en entrevistas para aquellos investigadores estudiosos de la sociología de la cultura u otras áreas similares. En este trabajo, contextualizamos y contribuimos a este debate. Revisamos las ideas de Martin y defendimos la idea de que las entrevistas en profundidad realmente son válidas y que existen favorables antecedentes en su aplicación. Por lo tanto sí son necesarias al investigar este tipo de fenómenos. Construimos esta contra-respuesta desde tres ángulos: epistemológico, teórico y metodológico. Haciendo nuestra defensa de este tipo de entrevistas, también damos cuenta de la manera en que científicos sociales implementan formas innovadoras para complementar su función, tal como sucede en el análisis de redes sociales.

Palabras clave: métodos cualitativos, entrevistas en profundidad, epistemología, sociología de la cultura, John Levi Martin. 


\section{Introduction}

In the social sciences, the study of subjectivity is not synonymous with the study of individuality. Despite the fact that individuals are a central unit of information, what social scientists need to get is something "sui generis" -in Durkheim's words- emerging from different forms of social interaction. This "sui generis" dimension has been observed in structured behaviors or patterns of interaction wherein positions are relevant, but cognitive processes have been largely neglected. On the other hand, "sui generis" character can be observed in more symbolic aspects, which unavoidably lead us to the concept of culture.

How do we investigate culture from any formal definition? Is a specific conceptual definition indispensable? Or should we to query culture upon different sets of definitions? It is worthwhile to wonder about the importance of epistemological underpinnings of research in the cultural field, taking into account "what people say." To attain valuable responses in research it is necessary to adopt a clear argumentative position regarding "qualitative" and "quantitative" methods. Unfortunately, for many, the discussion remains "more about what should and should not be considered qualitative than about the relative merits of quantitative and qualitative approaches to human study" (Preissle 2006:689).

This essay provides a different approach to the aforementioned considerations. It focuses on the usefulness of in-depth interviews as a method for investigating cultural phenomena. This type of interview is the meaning comprehension that people produce around specific topics. One or more encounters between interviewer and interviewee should generate an increasing level of complexity, namely semantic relationships, connection between facts and motives, judgments, etc. Consideration of questions around this technique is valid because there remains a shallow understanding of the basis, goal, and ultimate sense of in-depth interviews for obtaining valid and reliable knowledge.

Scholars relying on basic, vague, or obvious definitions of in-depth interviews reveal a lack of knowledge and a concerning level of "take for grantedness" of the method, which makes qualitative research (and specifically in-depth interviews) "vulnerable" to critique. Take, for example, this definition of qualitative interviewing given by Rubin and Rubin: "The responsive interviewing model relies heavily on the interpretative constructionist philosophy, mixed with a bit of critical theory and then shaped by practical needs of doing interviews. The model emphasizes that the interviewer and interviewee are both human beings, not recording machines, and that they form a relationship during the interview that generates ethical obligations for the interviewer" (2005:30).

Is this an indirect message to representatives of what Pitirim Sorokin called "quantophrenia" in the 1950s? Is it an ethical declaration or intellectual distinction? This way of defining research techniques -in-depth interviews in this case- does not fit with an understanding of the fundamentals and limitations of carrying out reflexive research. In making this argument, we challenge definitions from a post-structuralist program that connects qualitative interviews with emotions, recalling personal situations, even exerting therapeutic function.

This work aims to contribute to the defense of in-depth interviews, responding to the thorough and provocative paper written in 2010 by John Levi Martin titled "Life's a beach but you are an ant, and other unwelcome news for the sociology of culture". In it, Martin evaluates and criticizes the purpose and feasibility of interviews to study culture. Here, we begin with detailing Martin's critique and outlining the 
debate which it sparked. We then present a three-angled defense of in-depth interviews, drawing on epistemological, theoretical, and methodological concerns.

\section{Martin's critique and the interview debate}

One of the objectives of John Levi Martin's work is to challenge the idea that we can question culture as a system of meanings, getting into 'the heads' of individuals. According to the author, this idea leads investigators to do research "that involves probing informants as to how they make connections between subjective elements and attempting to reconstruct the culture from connections they make" (Martin 2010:228).

The author assumes that our minds have structural limitations (cognitive limitations) that should lead us to cast doubt on the reliability of information based on thoughts, meanings or any mental process. The mind is relatively simple if we compare it to the complexity of the social environment. Martin adds that this complexity "is not an attribute of environments or objects, but rather a relationship between minds and objects" (Martin 2010:230). Briefly, these cognitive limitations are:

1) Generically, we have a limited and low mental process.

2) Our memory is extremely limited and essentially parsimonious.

3) Our connections between categories are fuzzy.

4) The relationship among ideas is highly influenced by linguistic forms.

5) Conscious processes (reasoning why) are not efficient, reflecting more intuitive and simple processes behind our actions.

Martin does not deny that the aforementioned features allow us to be "social beings" and act in an efficient way. For instance, being parsimonious or selective with respect to stimuli from the environment can reduce the complexity of the social environment. However, he does not consider our cognitive skills so "effective" as to be good sources of information or at the same level of complexity as the environment. In this regard, the author insists that even though interactions are complex, "this is compatible with an understanding of our basic mental structures as being quite simple" (Martin 2010:239).

Clearly, as Martin acknowledges, it is a mistake to look inside people's minds for evidence that reflects their highly complexity social environment. At least, we should not have high expectations about what we will find related to the broadly accepted notion of culture, which he defines as "a complex web of meanings" (Martin 2010:228). More directly, Martin states the following with respect to in-depth interviews and the assumed usefulness to study cultural phenomena: "[I]f we want to learn about culture, the last thing we should do is to conduct in-depth interviews with a selection of informants, any more than we would expect to strike gold by asking them for whatever change is in their pockets" (2010:240).

While in-depth interviews have been used to study the meaning-making process in relation to very complex issues (e.g., Lamont 2000), Martin challenges social scientists who rely on such methods. Several prominent researchers have responded to this challenge. Lamont and Swidler (2014) caution against "methodological tribalism," defending interview methodology as appropriate (and often ideal) for addressing questions of social boundaries, status hierarchies, and other phenomena. Similarly, Pugh (2013) maintains that critiques of interview methods are largely founded on flawed understandings. She argues that contradictory accounts of motivation across (or within) interviews may in fact be analytically 
useful in the study of culture, which is itself complex and often seemingly contradictory. Responding to Pugh, Vaisey (2014) defends the dual process model of culture and advances the negative implications of this model for in-depth interviews. He questions the utility of interviews alone for connecting talk to implicit cultural content. Lizardo (2012), too, illustrates the complexity of measuring the relationship between the embodiment of culture and the retrieval or performance of cultural contents, suggesting that the assumption of an inherent link between the two remains problematic. Vila-Henninger (2015) draws on cognitive neuroscience research to reveal limitations in the overall debate between interview and survey researchers in the sociology of culture. Each method, he suggests, is useful for retrieving cultural information, though they get at participant memories through different mental systems. A better understanding of each and collaboration between the two are necessary.

It is clear that contentions remain over the issues that Martin helped to raise. To advance this debate, the following section will analyze and challenge his initial assumptions on epistemological, theoretical, and methodological grounds.

\section{Three angles to defend in-depth interviews}

Similar to Guba and Lincoln's portrayal of differences between paradigms in the social sciences, we address Martin's argument from three angles: epistemological-ontological, theoretical, and methodological. In presenting each angle, we refer to literature from the sociology of culture and relational sociology.

\section{1) Epistemological-ontological angle}

This double angle considers the nature of the relationship between the knower and what can be known. As Judith Preissle states, it is an analysis "at what many consider to be the most abstract level are the philosophical assumptions embedded in any study: the epistemologies, ontologies and axiologies that the researcher presupposed" (2006:668). In this section, we have preferred to address the epistemological side with an emphasis in cognition. While the ontological question about what the nature of reality is, in the context of this work, is directly a question about what culture is. Consequently, we have preferred to go over this issue in the Theoretical Angle section.

Shore acknowledges that "modern views of mental representation have tended to fall into two theoretical camps: realistic and nominalist" (1996:238). Following the latter distinction, the epistemological approach to in-depth interviews in cultural inquiry has been in general nominalist, assuming that reality, as unit of analysis, is a social construction.

In qualitative research and specifically for researchers carrying out in-depth interviews, the constructed representations about the world that subjects are able to manifest are the main source of scholarly knowledge. In other words, "we know the world only through our representations of it" (Denzin 2001:23). These representations can only be known through an "emic" perspective. This means interpreting thoroughly subjects' meanings of their own actions and of others' actions. This emic perspective is carried out within specific interpretative contexts.

In contrast, Martin's position is realistic with respect to researching culture when one considers that trying to grasp meanings through cognitive human processing may be naïve. The author considers culture as something that is out there, potentially "attainable" by the human mind. Nevertheless, such "attainability" 
is not possible. The human mind is limited in its ability to understand an external object given internal cognitive capacities.

The epistemological issue that Martin lays out can be better addressed outside the philosophical field. In doing so, we consider "what is possible to know, by whom and how about culture" in a way more related to social empirical research. In this regard, research focused on human cognitive processes depicts valuable pieces of evidence. This challenges Martin's thesis about both our capability as subjects of processing social reality in a coherent way and, as researchers, to comprehend subjects' constructed meanings as product of the aforementioned process.

There are interesting and complex processes in our minds, which matter from a constructivist standpoint regarding culture. Apart from considering that our cognitive processes are highly social, it is imperative to consider endogenous aspects, which psychologists have explored. Whatever we have "out there", such as interactions, shared meanings, or material culture, is apprehended by internal mechanisms. Among these types of mechanisms is the process of categorization. Despite our limited capacity to understand cultural elements, the process of categorization is a way "to survive" socially. Consequently, verbal manifestation through interviews is one way (among others) that can mediate our knowledge of culture through people's minds.

\section{Cognitive processes and culture}

According to Martin, mental processes are insignificant with respect to the complexity of the environment. However, researchers adopting a cognition approach have demonstrated that there are important mental processes that should be considered by the sociology of culture.

Following Jean Mandler, the cognitive approach sees in our mental processes a complexity centered on relations between categories which allow us to organize our experience. They are abstract entities not only based on experiences but imagination as well. According to the cognitive approach, people make use of complex schemes in order to work through challenging questions or situations. Therefore, these cognitive processes can be grasped as cultural understandings which are culturally shared. However, this does not mean that we are actors of permanent awareness and reflexivity with respect to mental processes. As Lakoff argues, "most categorization is automatic and unconscious, and if we become aware of it at all, it is only problematic cases" (2008:6).

Another important issue is memory. It is impossible to deny our limited capacity to recall information. Similarly, Paul DiMaggio presents two kinds of cognition: (1) Automatic cognition is related to uncritical knowledge upon culturally available schemata. It has two important consequences. The first is about methodology, which leads us to grasp "taken-for-granted assumptions which subjects may not have easy verbal access" (DiMaggio 1997:269). Secondly, this kind of cognitive process tells us something about how culture works, allowing us to use schema as the central unit of analysis. (2) Deliberative cognition refers to a set of cognitive processes related to critical thinking. However, this type of thinking is only possible under specific conditions such as attention toward a problem, strong motivation, or when a used schema fails when it faces inconsistent evidences. For instance, in this regard, researchers who believe that cognitive elements are inside people's minds and that the job of interviewers is to collect them, have developed techniques such as "graphic elicitation", visual tools complementing interviews which can expand, modify, and even refute a researcher's emerging conceptualization. 
Both kinds of cognition are crucial in order to demonstrate how uni-dimensional Martin's point of view is. It is probable that some techniques are not efficient in order to "get" reliably cognitive elements from people. However, this is only one side of our mental process. As DiMaggio states, "research on automatic versus deliberative processing may help sociologists to determine what to do with the widely believed but theoretically inert notion that both institution and agency are central to social life" (1997:272). Similarly, Nairn and colleagues (2005) and Jacobsson and Åkerström (2013) understand that interviews are not a failure when they are not reliable from a realistic or positivist perspective. There are other dimensions that matter when we seek to understand human behavior and culture specifically. For instance, the way that interviewees communicate may inform what they say, opening new routes of research culture.

Vaisey uses both types of cognition (presenting a dual-process model of culture) to defend a conception of culture that links values and action. He presents his proposal regarding how to face two kinds of consciousness as follows: "Research in a number of areas points toward a dual-process model of cultural cognition: actors are driven primarily by deeply internalized schematic processes ('the elephant' / practical consciousness / habitus), yet they are also capable of deliberation and justification ('the rider' / discursive consciousness) when are required by the demands of social interaction" (2009:1687).

Vaisey's thesis has important methodological implications. Interviews are not good when people make judgments with respect to their actions, which are based on unconscious cognitive processes and do not say much about real motives behind a person's behavior. Later, the author states that, despite the fact that interviews would not be a good strategy for tool kit-repertoire theory, they are for the means-ends theory (2009:1670). When Vaisey presents the empirical consequences of this approach, he advises us about what kind of information we can access through interviews: "Because discursive consciousness is largely uninvolved in routine moral decision making, interview respondents will either (a) tend to explain their behavior in intuitive terms without a clear substantive referent or (b) offer multiple 'loosely coupled' logic of justification to support their judgments" (2009:1690).

This moral decision-making does not always follow the ordinal logic action-justification. According to C. Wright Mills, justifications can precede action: "To term them justification is not to deny their efficacy. Often anticipations of acceptable justifications will control conduct... (also) Often he [the actor] is finding new 'reasons' which will mediate action. Thus, we need not treat an action as discrepant from 'its' verbalization, for in many cases, the verbalization is a new act" (1940:907).

Finally, these two types of cognition help us to understand that the limited capacity of our mind is an important feature to consider when we want to study culture through discourse. For instance, as Zerubavel states, "most of the concepts we use to organize our experience are not clear-cut and sharply delineated but, rather, vague and often modified by such 'hedges' as 'largely,' 'sort of,' 'quite,' 'almost,' or 'more or less', until recently, such an ability to process fuzzy categories and negotiate subtle nuances" (1993:74). This fuzziness of categories is discussed further in the following section.

\section{2) Theoretical angle}

In this section, we focus on the theoretical aspects of culture as object of knowledge. There are three topics related to this part. One is the concept of culture that Martin uses in order to assess how useful interviews may be. The second is a theoretical concern related to the concepts of meaning and motives 
and their relationship with language. Finally, there are theoretical aspects related to categorization and symbolic boundaries in the sociology of culture.

\section{Discussion on culture}

An important aspect of Martin's work is to understand his assumption about the concept of culture. The complexity of culture would be an "elephant sleeping in a bathtub" (Martin 2010:240). He says that culture is external and can never be conceived within our minds, nor is it shared through phenomena like "intersubjectivity". Martin may be right in considering that scholarly reflections on qualitative interviews frame the technique as communicative interactions aimed at identifying meanings regarding others' meanings and actions, which therefore remain in reproduction. However, Martin's work lacks an explicit definition of what culture is. To build a defense of in-depth interviews, there are interesting conceptualizations of culture that must be taken into consideration.

Clifford Geertz claims that culture should be understood as a way that people organize action and experience in different contexts. Those contexts have plenty of symbols and meanings but these contexts are imbalanced and they do not have the same symbolic intensity. Consequently, Geertz provides the elements to understand variation with respect to cultural coherence among different contexts. The relationship between meanings and practices has been crucial in the current debate over defining culture. Ann Swidler, in a paradigmatic paper, stated that "culture influences action not by providing the ultimate values toward which action is oriented, but by shaping a repertory or 'tool kit' of habits, skills, and styles from which people construct 'strategies of action'" (1986:273). In this regard, Paul DiMaggio states that "research in cognitive psychology strongly supports the toolkit over the latent-variable view and suggests that typical toolkit is very large indeed" (1997:267). Following DiMaggio, an example of these strategies would be that when people speak about themselves, they try to seem coherent and use cultural elements as symbolic tools.

If culture can be defined as a "toolkit", the interaction between practices and symbols are central to these strategies. Practices (the material world) and Symbols (the cultural world) are interpenetrated. Thus, action has to be associated with the analysis of discursive practices as the constitution of a duality (Breiger 2000, Breiger 2002). An in-depth interview can be considered a discursive practice as well as an object of analysis itself.

\section{Motivation, meaning, and discourse}

Martin's work casts doubt on the capacity of individuals to recall facts, among other points of weakness. However, we can consider a different way to analyze discourse, which contemplates the relationship between discourse and culture mediated by the concept of "motivation" and, alternatively, through the concept of "classification". C. Wright Mills (1940), in a classical essay, discussed some ideas about the role of discourse in researching culture. The main criticism from Mills is that language is assumed as an external manifestation or concomitant of something prior, more genuine, and "deep" in the individual or inside the individuals' mind, as Martin states.

Mills prefers the idea that language aims toward potential actions. This means that language is important for understanding motives in a similar way that Alfred Schutz put forward in social phenomenology. Moreover, for Mills, "to explain behavior by referring it to an inferred and abstract 'motive' is one thing. 
To analyze the observable lingual mechanisms of motive imputation and avowal as they function in conduct is quite another [later he adds] then, we must indicate mechanisms of the linkage of vocabularies of motive to systems of action" (1940:904).

One can see that what people say becomes important when discourse has a function in the contexts of systems of actions. Mills calls attention to the relationship as the connection between our cognitive process and action. As was seen above, discourse as verbalization of motives can be fuzzy and incoherent. In this regard, Anne Norton argues that "Language is not only a mean by things are named but the schema in which things are placed in relation, and the medium in which those names and those relations are changed" (2004:12). The latter might add more complexity to analyzing social reality through in-depth interviews, but it has to be assumed as a part of a specific way to understand culture from individuals.

Let us consider the example of "The Politics of Elective Belonging" by Mike Savage and colleagues. The abstract states: "I pursue this theme through examining the narratives which different sorts of people articulate in talking about their attachment to their residential locale. Building on arguments first developed in Globalization and Belonging (...) I assess the scope of what Gaynor Bagnall, Brian Longhurst and I called "elective belonging", the way that middle class people claimed moral rights over place through their capacity to move to, and put down roots in, a specific place which was not just functionally important to them but which also mattered symbolically" (2010:115, emphasis added).

Savage and colleagues attempt to comprehend symbolic aspects of housing, which are the meaning and motivations that become a rationale for residential attachment. The authors mention articulation as an activity of interviewees. Obviously, the scope to which the author refers assumes a categorical sense.

\section{Classification, symbolic boundaries and discourse}

One of the most common dichotomous categories of analysis is the dyad structure vs. agency. Holland (2013) studied this dichotomy by exploring explanations of social inequality given by American MBA students. The discourses were assembled upon both structural and individual explanations. These discourses only became sensible for the subjects when they were able to state strong statements about human nature. By establishing the nature of human beings, they were able to set boundaries between what is realistic and what is not in order to better explain and handle social inequality.

The aforementioned research is an example of the need to grasp the way in which subjects construct coherent representations. These representations might be based on categories, which can be totally opposed in other arenas. Boundaries constructed in a particular cultural system might be different from those constructed in other cultural systems. Moreover, the boundaries and rationales are generally different from other types of systems like politics or art.

Social boundaries have been a core topic in the sociology of culture. Michele Lamont has become a prominent researcher studying symbolic exclusion and hierarchy from people's discourse, adopting a tight relation with Bourdieu's work on symbolic power. Lamont, in her well-known work Money, Morals and Manners, defends qualitative interviews as an important technique for investigating cultural boundaries, as the following excerpt lays out: "[Qualitative interviews] are superior to survey questions for studying symbolic boundaries, as they let interviewees themselves describe their standards of evaluation and led the researcher toward the most appropriate analytical categories... [and] allow us to infer how 
respondents draw boundaries by focusing on the implicit criteria of purity at work during the interviews" (1992:15).

Drawing boundaries, as Lamont states, is a crucial process that has been grasped using in-depth interviews. Nevertheless, it is worthwhile to consider the lack of consistency and fuzziness of boundaries among categories or concepts in cultural terms. This has been a central topic of discussion among scholars that define the process of classification as a crucial part of culture.

Our minds categorize and classify phenomena. This is a symbolic process with practical objectives and consequences. Martin argues that the central problem is not that "we do not remember well" (2010:232) but that our records are unbounded and contain fuzzy connections. Like Martin, the researchers Goldberg \& DiMaggio (2012) describes the process of classification based on work from neuroscience and the neurolinguistic sciences. He maintains that: (1) Tt is not a binary process; there are ambiguous classifications and fuzzy logic. The shape of the relationship is reticular. (2) Categories are ambiguous and embedded in complex semantic networks. (3) Categories are only meaningful insofar as they relate to one another and (4) People do not always have the awareness to articulate the categories that are the basis of their behaviors. Most processes are unconscious and they are dispositions, as Pierre Bourdieu has defined.

Fuzziness should not be used an argument to neglect in-depth interviews, but is a condition that any researcher has to face and, therefore, look for better ways of gathering and analyzing oral information. Our classification tends to be ambiguous, contradictory and unsteady throughout time. In-depth interviews imply this kind of fuzzy classification within and between individual discourses.

In order to illustrate cultural distinction through discourses, we may draw on Mendez, who states: "This paper explores in-depth interviews on aspects of middle class identity in a neoliberal age, taking the case of Chile's rapid and stark transition to a neoliberal economic model which was imposed by a dictatorship but later reproduced during democracy. The paper reveals that there are no challenges to middle class identities (e.g. from the working class, or peasants). In this respect, these are neo-liberal middle class identities in that their way of thinking is preconditioned by market dominance" (2008:220).

Despite the fact that in this work there are no explicit epistemological and methodological assumptions, we can note several examples of discourses that mirror distinctions and cognitive schemes:

"Interviewee: -In my opinion, the problem is that we don't have a distinctive Chilean culture, everything is about going to McDonald's, 'the shopping centres' (in English in the original) and not the 'centros comerciales' (shopping centres).

Researcher: -And would you find it better if it was more 'European' instead?

Interviewee: - I would find it superb! (laughs), what a nightmare, I'm such a snob! Well, anyway, Europe is a different thing, the Europeans do well and know how to live well, they not only work, but know when to stop, they have a coffee and chat, they have good taste... I guess that it is clear that we should be imitating Europe instead, they do have culture" (Mendez 2008:232).

It is difficult to grasp unconscious processes from these discourses, but it is also hard to neglect the evidence of the way that the actor explains their actions and establishes boundaries, classifications, and 
categorical connections. There is no doubt that the researcher's object of study cannot be addressed by any other methodological strategy.

\section{3) Methodological angle}

This angle focuses on technical issues. It aims to respond coherently to the possibility of getting empirical data with epistemological and theoretical principles. This is what most students and scholars mean when they declare an investigation as "qualitative research" because "it emphasizes the "how'-procedures, techniques, practices-rather than the "what' and the "why'" (Preissle 2006:690). However, this focus cannot be isolated from epistemological issues. For instance, Rubin and Rubin describe philosophical fundaments using technical aspects of research when they state that "The positivist philosophy underlies experiments, surveys, and other statistical studies and imitates the ways in which those in the natural sciences go about their work" (2005:19).

Techniques such as in-depth interviews need to be settled in solid epistemological principles, which also need to be related to the nature of cognitive processes to which those techniques are connected. In this regard, Martin can elaborate his criticism of in-depth interviews because he begins with an ontological (realism) and epistemological (empiricism) hypothesis that yields a distinction, for instance, between false or real memory.

Having exposed some contours of the philosophical underpinnings of in-depth interviews, it is necessary to consider a more practical dimension of this technique. However, reviewing procedural aspects of indepth interviews is not the main contribution of this section. Instead, the aim is to relate this type of interview with methods that have not been associated to concepts such as meaning, motivation, or language.

\section{Duality of meaning and practice in social network analysis}

In-depth interviews have been utilized and discussed by different disciplines, which have not necessarily always relied on oral sources. For example, historians have been concerned with reliability and validity of oral sources; however, they cannot dispense of them when they face a lack of written resources or when it is necessary to contrast data coming from that kind of source. The discourse of interviewees and interviewers are embedded in the context of macro-level events and social relations, which can be understood as the frame of what people are saying.

In the social sciences, qualitative interviews have been acknowledged as complementary to structural methods. In this regard, Pager and Karfin (2009) considered it necessary to complement models of statistical discrimination exploring employers' group-level attributions. In-depth interviews were the main way to understand complex processes of deep personal attitudes and their formation, although the emergent conclusion might actually be hypotheses for further testing.

Michele Lamont (2000) was not wrong when she claimed that the process of "meaning-making" is a dimension that needs to be developed in social science fields like social inequality or discrimination as a renewed agenda. The rationalistic paradigm has several universalistic assumptions that an interpretative approach can unveil. The latter statement is probably a challenge to structural research programs. This is 
a field of sociological knowledge which has been very disconnected from qualitative interviews; however, some things seem to be changing in realms such as social networks studies.

It is hard to see the application of in-depth interviews to social network analysis, which has traditionally been based on positivist and structuralist principles. According to Fuhse and Mutzel, "networks are thus not seen as mere analytical constructs, but as real social structures with three dimensions: the structure of social relationships; the individual actors and their connections; and the meaning associated with networks and their connections" (2011:1068). This need to combine cultural aspects such as meaning and motivation with approaches that consider practices as central concerns is a reaction to criticisms against social network analysis. The main weakness of social network analysis, according to critics, would be to neglect people's motivations when they are pursuing particular relationships and dropping others. This means that the actors actively construct their networks; therefore, "an analysis of structures and connections has to be complemented with a concern for meaning, for the linguistic forms, narratives, cultural practices, and expectations embodied in networks" (Fuhse and Mutzel 2011:1078).

The methodological dimension of in-depth interviews can be considered highly flexible and useful. This means that this kind of technique has its own merit and may also be part of other research agendas that, some years ago, excluded any kind of intensive or qualitative components. A valuable example is that more scholars are striving to understand the meaning associated with social networks and explore their context through in-depth interviews. In fact, Mortelmans and Verheyen (2011) reconstructed network paths using in-depth interviews in order to grasp the supportive interactions that women establish after a relational breakup. To a lesser extent, Pirskanen and colleagues (2015) used social network diagrams as a visual method in order to conduct interviews on sensitive topics and encourage people to remember and talk about issues that they would have neglected in other contexts.

\section{Conclusion}

There are diverse philosophical and ideological underpinnings of qualitative methods and in-depth interviews in particular. Several of them should be challenged. For some scholars, interviews are a social action or interpretative practice rather than a method for gathering information. Thus, these would be reflexive, dialogic, or performative interviews. Also, there are proposals striving to save failed interviews.

Considering the positions illustrated above, we do not claim that Martin's criticisms of in-depth interviews are entirely unworthy. His position becomes more acceptable if we accept his epistemological and theoretical assumptions. However, using alternative principles with respect to his assumptions, it is possible to understand discourses and qualitative interviews in a different way.

It has been claimed that culture is a phenomenon based on individual cognitive processes, but this should not mean that culture and individual cognitive process are the same. We can learn what people think, mean, and do fruitfully as a part of any cultural context and not as an output or translation of a more complex environment. We should not expect consistent and coherent ideas from discourses because human beings process reality in fuzzy ways. The real problem lies in the level of complexity of our methods and their ability to analyze such tangled meanings, motivations, and justifications.

In regards to the overall value of interviews, we have maintained that they are indeed worthy without giving up scientific principles of validity and reliability. As Lamont states, "social scientist have devised 
various techniques to minimize 'distortions' and have continued to produce qualitative studies of great interest and importance" (1992:19).

We have also introduced methodological considerations regarding other approaches to culture, including the integration of interviews and other methods. For instance, social network analysts rely on sophisticated algorithms and computational procedures. Furthermore, they have created an abstract corpus transforming social network analysis into a consistent theoretical approach rather than a mere technique. However, when social network analysts observe friendship ties, it becomes necessary to unpack what a "friendly tie" truly means to participants. In-depth interviews are a useful way to understand these and others phenomena, though it is necessary to remain aware of their possibilities and limitations. With respect to the latter, John Levi Martin's article is mandatory reading.

In conclusion, Martin's article does offer "unwelcome news" for social scientists who fail to address (or who are unaware of) the epistemological, theoretical, and methodological fundamentals of in-depth interviews, or of contemporary advances in qualitative methodology. In this paper, we have aimed to outline relevant concerns in these areas, which we hope will strengthen interview methodology and the study of culture broadly.

\section{Bibliography}

Breiger, R.L. 2002. Writing (and quantifying) sociology, pp. 90-112. In: J. Monroe (ed) Writing and revisiting the disciplines. Ithaca, NY and London: Cornell University Press.

Breiger, R.L. 2000. A tool kit for practice theory. Poetics 27(2-3): 91-115. doi: 10.1016/S0304422X(99)00026-1

Denzin, N. 2001. The reflexive interview and a performative social science. Qualitative Research 1(1):2346. doi:10.1177/146879410100100102.

DiMaggio, P. 1997. Culture and cognition. Annual Review of Sociology 23: 263-287. doi:

10.1146/annurev.soc.23.1.263

Fuhse, J. \& Mutzel, S. 2011. Tackling connections, structure, and meaning in networks: quantitative and qualitative methods in sociological network research. Quality and Quantity 45(5): 1067-1089. doi: 10.1007/s11135-011-9492-3.

Goldberg, A. \& DiMaggio, P. 2012. Where do social categories come from? A comparative analysis of online interaction and categorical emergence in music and finance. New Jersey: Princeton University.

Holland, C. 2013. An empirical analysis of the structuration of American ideologies about economic justice." Qualitative Sociology Review 9(4): 84-99.

http://www.qualitativesociologyreview.org/ENG/volume27.php

Jacobsson, K. \& Åkerström, M. 2013. Interviewees with an agenda: learning from a 'failed' Interview. Qualitative Research 13(6): 717-734. doi: 10.1177/1468794112465631. 
Lamont, M. 2000. Meaning-making in cultural Sociology: broadening our agenda. Contemporary Sociology 29(4): 602-607. http://www.jstor.org/stable/2654561

Lamont, M. 1992. Money, morals and manners. The culture of the French and the American upper-middle class. Chicago and London: The University of Chicago Press.

Lamont, M. \& Swidler, A. 2014. Methodological pluralism and the possibilities and limits of interviewing. Qualitative Sociology 37(2): 153-171. doi: 10.1007/s11133-014-9274-z

Lakoff, G. 2008. Women, fire, and dangerous things. What categories reveal about the mind. Illinois: The University of Chicago Press.

Lizardo, O. 2012. Embodied culture as procedure: rethinking the link between personal and objective culture. Collegium 12: 70-86. http://www.helsinki.fi/collegium/journal/volumes/volume_12/index.htm

Martin, J. 2010. Life's a beach but you're an ant, and other unwelcome news for the sociology of culture. Poetics 38(2): 228-243. doi: 10.1016/j.poetic.2009.11.004.

Mendez, M. 2008. Middle class identities in a neoliberal age: tensions between contested authenticities. The Sociological Review 56(2): 220-237. doi: 10.1111/j.1467-954X.2008.00785.x.

Mills, C. Wright. 1940. Situated actions and vocabularies of motive. American Sociological Review 6: 904913. http://www.jstor.org/stable/2084524

Mortelmans, D. \& Verheyen, W. 2011. A dyadic view on the post-separation network of single mothers. Qualitative Sociology Review 7(3): 72-96.

http://www.qualitativesociologyreview.org/ENG/volume20.php

Nairn, K; Munro, K; Smith, A.B. 2005. A counter-narrative of a 'failed' interview." Qualitative Research 5(2): 221-244. doi: 10.1177/1468794105050836

Norton, A. 2004. 95 theses on politics, culture, and method. New Haven and London: Yale University Press.

Pager, D. \& Karafin, D. 2009. Bayesian bigot? Statistical discrimination, stereotypes, and employer decision making. The Annals of the American Academy of Political and Social Science 621(1): 70-93. doi: $10.1177 / 0002716208324628$

Pirskanen, H. et.al. 2015. Researching children's multiple family relations: social network maps and lifelines as methods. Qualitative Sociology Review 11(1): 50-69.

http://www.qualitativesociologyreview.org/ENG/volume32.php

Preissle, J. 2006. Envisioning qualitative inquiry: a view across four decades. International Journal of Qualitative Studies in Education 19(6): 685-695. doi:10.1080/09518390600975701. 
Pugh, A. J. 2013. What good are interviews for thinking about culture? Demystifying interpretive analysis. American Journal of Cultural Sociology 1(1): 42-68. doi: 10.1057/ajcs.2012.4

Rubin, H. \& Rubin, I. 2005. Qualitative interviewing. The art of hearing data. Thousand Oaks, London and New Delhi: Sage.

Savage, M. et.al. 2010. The politics of elective belonging. Housing, Theory and Society 27(2): 115-161. doi: 10.1080/14036090903434975.

Shore, B. 1996. Culture in mind. Cognition and the problem of meaning. Oxford: Oxford University Press.

Swidler, A. 1986. Culture in action: symbols and strategies. American Sociological Review 51(2): 273-286. http://www.jstor.org/stable/2095521

Vaisey, S. 2014. Is interviewing compatible with the dual-process model of culture? American Journal of Cultural Sociology 2(1): 150-158. doi: 10.1057/ajcs.2013.8

Vaisey, S. 2009. Motivation and justification: a dual process model of culture in action. American Journal of Sociology 114(6): 1675-1715. doi: 10.1086/597179.

Vila-Henninger, L. A. 2015. Toward defining the causal role of consciousness: using models of memory and moral judgment from cognitive neuroscience to expand the sociological dual-process model. Journal for the Theory of Social Behaviour 45(2): 238-260. doi: 10.1111/jtsb.12068

Zerubavel, E. 1993. The fine line. Illinois: The University of Chicago Press.

Received: 20 Oct 2016

Accepted: 29 Nov 2016 